OPEN ACCESS

Edited by:

Xiaonan Wang,

National University of Singapore,

Singapore

Reviewed by:

Carlos Santiso,

Inter-American Development Bank,

United States

Jon Crowcroft,

University of Cambridge,

United Kingdom

Anwaar Ali,

University of Cambridge,

United Kingdom, in collaboration with

reviewer JC

*Correspondence:

Hang Xiong

hxiong@hzau.edu.cn

Specialty section:

This article was submitted to

Blockchain for Good,

a section of the journal

Frontiers in Blockchain

Received: 29 March 2019

Accepted: 04 February 2020

Published: 21 February 2020

Citation:

Xiong $H$, Dalhaus T, Wang P and

Huang J (2020) Blockchain

Technology for Agriculture:

Applications and Rationale.

Front. Blockchain 3:7.

doi: 10.3389/fbloc.2020.00007

\section{Blockchain Technology for Agriculture: Applications and Rationale}

\author{
Hang Xiong ${ }^{1 *}$, Tobias Dalhaus ${ }^{2}$, Puqing Wang ${ }^{3}$ and Jiajin Huang ${ }^{4,5}$ \\ ${ }^{1}$ Macro Agriculture Research Institute, College of Economics and Management, Huazhong Agricultural University, Wuhan, \\ China, ${ }^{2}$ Agricultural Economics and Policy Group, ETH Zürich, Zurich, Switzerland, ${ }^{3}$ College of Economics \\ and Management, Wuhan Polytechnic University, Wuhan, China, ${ }^{4}$ The Development Research Center of Shanghai Municipal \\ People's Government, Shanghai, China, ${ }^{5}$ School of Economics, Fudan University, Shanghai, China
}

The blockchain is a ledger of accounts and transactions that are written and stored by all participants. It promises a reliable source of truth about the state of farms, inventories and contracts in agriculture, where the collection of such information is often incredibly costly. The blockchain technology can track the provenance of food and thus helps create trustworthy food supply chains and build trust between producers and consumers. As a trusted way of storing data, it facilitates the use of data-driven technologies to make farming smarter. In addition, jointly used with smart contracts, it allows timely payments between stakeholders that can be triggered by data changes appearing in the blockchain This article examines the applications of blockchain technology in food supply chains, agricultural insurance, smart farming, transactions of agricultural products for both theoretical and practical perspectives. We also discuss the challenges of recording transactions made by smallholder farmers and creating the ecosystem for utilizing the blockchain technology in the food and agriculture sector.

Keywords: blockchain technology, food supply chain, agricultural insurance, smart agriculture, smart contract

\section{INTRODUCTION}

The use of data and information becomes increasingly crucial for the agriculture sector to improve productivity and sustainability. Information and Communication Technology (ICT) substantially increases the effectiveness and efficiency of collecting, storing, analyzing and using data in agriculture (Walter et al., 2017). It allows agricultural practitioners and farming communities to easily obtain update-to-date information and thus make better decisions in their daily farming (Kaddu and Haumba, 2016). For example, remotely sensed data on soil conditions can support farmers' crop management (Brown, 2015), mobile phones reduce information cost and thus promote farmers' access to markets and financial support (Kaske et al., 2018), and the development of Global Positioning System (GPS) facilitates filed mapping and machinery guidance and crop scouting (Yousefi and Razdari, 2015).

\section{From ICT to Blockchain}

Information and Communication Technology does not avoid bias in the collection and use of data. Individuals operating ICT always are motivated to use data in a way that favors their own interest. For example, stakeholders' preference in a multi-criteria decision is highly influenced by the organization they represent (Collier et al., 2014) and NGOs can have a disproportionate focus on the issues to address due to its interest (Ngo Monitor, 2015). An effective way of avoiding such 
bias is to make data manipulation difficult or even impossible by distributing the power of data management to a very large number of individuals.

A blockchain is a ledger in which agents take turns recording information on the process of generating, transacting and consuming a product or service. The ledger is collectively managed by all participating parties typically through a peerto-peer network. A new record must be verified by the network before adding it to the blockchain. Any alteration to the recorded data should follow consensus decisionmaking protocol, meaning the majority of the parties involved should agree. In addition, an alteration to one record will lead to the alteration of all its subsequent records. It is, therefore, almost impossible to change in data recorded in a blockchain in practice. Blockchain is viewed as "an open, distributed ledger that can record transactions between two parties efficiently and in a verifiable and permanent way" (Iansiti and Lakhani, 2017). Blockchain is a transformative ICT that have the potential to revolutionized how data is used for agriculture.

\section{Potential Blockchain Technology Benefits for Agriculture}

The blockchain technology allows peer-to-peer transactions to take place transparently and without the need for an intermediary like a bank (such as for cryptocurrencies) or a middleman in the agriculture sector. By eliminating the need for a central authority, the technology changes the way that trust is granted - instead of trusting an authority, trust is placed in cryptography and peer-to-peer architecture. It thus helps restore the trust between producers and consumers, which can reduce the transaction costs in the agri-food market.

The blockchain technology offers a reliable approach of tracing transactions between anonymous participants. Fraud and malfunctions can thus be detected quickly. Moreover, problems can be reported in real-time by incorporating smart contracts (Haveson et al., 2017; Sylvester, 2019). This helps address the challenge of tracking products in the wide-reaching supply chain due to the complexity of the agri-food system. The technology thus provides solutions to issues of food quality and safety, which are highly concerned by consumers, government, etc.

The blockchain technology provides transparency among all involved parties and facilitates the collection of reliable data. Blockchain can record every step in a product's value chain, ranging a product's creation to its death. The reliable data of the farming process are highly valuable for developing data-driven facilities and insurance solutions for making farming smarter and less vulnerable.

This article reviews applications of the blockchain technology in the agriculture and food sector.

\section{APPLICATIONS}

In this section, we discuss four classes of applications in agricultural and food sectors: agricultural insurance, smart farming, food supply chain, and transactions of agricultural products.

\section{Agricultural Insurance}

Weather extremes threaten agricultural production, putting food security at risk (Lesk et al., 2016). Both, crop and livestock production are affected, and climate change is expected to further exacerbate weather extremes in the future (Lobell et al., 2011; Finger et al., 2018). Agricultural insurance schemes are traditionally a well-recognized tool to manage weather related risks. Here, farmers pay an insurance premium before the cropping cycle begins and receive an insurance payout whenever they experience a loss on their farm. Thus, the insurer bears all the insured risk and farmers are able to manage their financial exposure to weather extremes, i.e., financial losses caused by weather extremes. In addition, in case of weather threats that systemically affect all the insured farmers, the insurer can further hedge the systemic part of the risk with a reinsurance company (Miranda and Glauber, 1997).

Agricultural insurances differ with respect to how losses are assessed and consequently how payouts are triggered. Insurances that indemnify farmers based on a damage assessment that was made by an expert on the farm are denoted as indemnity-based insurances. Indemnity based insurances are able to precisely cover losses, however, they are prone to problems arising from asymmetric information problems (Just et al., 1999). More specifically, information on the riskiness of the agricultural production and production practices is asymmetrically distributed between farmer and insurer. Farmers are expected to be better informed about both which incentivizes adverse selection and moral hazard. The adverse selection indicates that farmers with a higher ex ante risk exposure are more likely to purchase insurance compared to farmers with lower risk. Moral hazard indicates that farmers shift to more risky production practices when being insured. Both phenomena lead to market failure of the insurance scheme if the insurer has insufficient information on the two cases. Thus, indemnity-based insurances are prone to costly damage assessment and need to implement measures to avoid problems arising from asymmetric information, such as deductibles. Moreover, productions that cannot be measured, e.g., grazed meadows, cannot be insured although leading to financial damage (Vroege et al., 2019).

Motivated by the drawbacks of indemnity-based insurances, the idea of index-based insurances was born either as an alternative or complement to the classical products (Turvey, 2001). Here the payout is not triggered by the loss itself but by a measurable index, such as rainfall at a nearby weather station (Barnett and Mahul, 2007; Barnett et al., 2008). If this weather station has sufficiently long historical weather records, both parties, the farmer and the insurer, have identical information about the insured value and moreover, farming practices have no impact on the insurance payout. Hence, adverse selection and moral hazard play no role and the technical procedure to trigger a payout became substantially simplified. Moreover, full insurance coverage without any deductibles is 
possible and payments can be made timely and automated just after an adverse weather event was measured. However, discrepancies between payout and on-farm loss can occur which is denoted as basis risk (Woodard and Garcia, 2008). Three sources of basis risk can occur. Spatial basis risk marks any differences between measured and on-farm weather, e.g., through spatial distance (Ritter et al., 2014; Dalhaus and Finger, 2016). Temporal basis risk indicates that an unprecise time window was chosen for index determination, e.g., whole year rainfall vs. growing season rainfall (Conradt et al., 2015; Dalhaus et al., 2018). Design basis risk summarizes all remaining sources, e.g., missing weather variables or biased technical implementation (Leblois et al., 2014).

Summarizing, index insurances are becoming an increasingly important risk management tool for farmers, while basis risk reduction is of central interest. Blockchain can contribute to improving index insurance in two dimensions. First, payments can be made timely and automated based on weather data that triggers the payout as defined in a smart contract. Second, weather information and other data sources, such as plant growth information or data collected by farm machinery, can be automatically integrated via a smart oracle improving basis risk reduction and making the index determination and payout process more efficient (Gatteschi et al., 2018). Smart contracts that integrate external data using smart oracles have already been proven useful in other crypto-economic applications (Harz et al., 2019).

First prototypes for smart index insurance contracts are already in preparation or launched. For instance, Etherisc ${ }^{1}$, a Swiss-based company, provides decentralized crop insurance based on blockchain technology that provides payouts based on weather data in DIP as native currency (DIP Decentralized Insurance Protocol tokens). Furthermore, WorldCover $^{2}$, an insurance provider based in New York City who provides index insurance contracts to smallholder farmers in Ghana, simulated the application of an Ethereum blockchain-based smart contract. Payouts would hence be made in the cryptocurrency Ether. Another smart crop insurance provider is $\mathrm{Arbol}^{3}$. At Arbol, a farmer can propose a contract that includes the premium payment, a payout and a weather event that triggers the payout. Afterward, an investor, serving as counterparty can agree to that proposed contract. Initial and final payments are made in Ether (Jha et al., 2018).

Besides the above advantages of decentralized insurances that are based on smart contracts making automated payouts, the usability of cryptocurrency payouts to compensate farmers needs to be proven in the field. Moreover, farmers, especially in the developing world, might not have access to the required infrastructure to participate in a decentralized blockchain-based insurance system. As a first solution, e.g., Etherisc proposes that third party organizations "[...] can offer payment gateways and integrations which remove the

\footnotetext{
${ }^{1}$ https://etherisc.com/, last accessed on September 25, 2019

${ }^{2}$ https://www.worldcovr.com/, last accessed on September 25, 2019

${ }^{3}$ https://www.arbolmarket.com/, last accessed on September 25, 2019
}

necessity to own cryptocurrency from the end customer" (Mussenbrock, 2017).

\section{Smart Agriculture}

Underlying the agri-food systems is the essential data and information on the natural resources that support all forms of farming. As shown in Figure 1, data and information flow while products flow from inputs to output through various value-adding stages as well as financial flow from output to inputs. Different actors and stakeholders generate and manage data and information as per their needs and capacities. Smart agriculture is featured by the utilization of ICT, internet of things (IoT), and various modern data collection and analysis technologies including unmanned aerial vehicles (UAV), sensors and machine learning. A key issue of establishing smart agriculture is developing a comprehensive security system that facilitates the use and management of data. Traditional ways manage data in a centralized fashion and are prone to inaccurate data, data distortion and misuse as well as cyber-attack. For example, environmental monitoring data is generally managed by centralized government entities that have their own interest. They can manipulate the decision-making related to data.

The blockchain technology serves to store data and information that various actors and stakeholders generate throughout the entire value-added process, from seed to sale, of producing an agricultural product. It ensures that the data and information are transparent to the involved actors and stakeholders and all recorded data are immutable. Figure 1 shows how what type of blockchain (permissioned or permissionless) used on what kind of platform (Ethereum or Hyperledger) along with which consensus mechanism [Proof of Work/Proof of Stake and (Practical) Byzantine Fault Tolerance] might be suitable to collecting data and information at different stages in crop agri-food systems. The blockchain technology generates security through decentralization rather "security of obscurity" that traditional technologies rely on (Ibm Institute for Business Value, 2015). Distributing data to stakeholders' computers all is less vulnerable to data loss and distortion than storing data in servers centrally managed by administrators. A blockchain is a database that contains timestamped batches of transactions and activities related to a product. Storing data in servers centrally managed by administrators are more vulnerable to loss and distortion than distributing them to servers on the Internet. The database is incredibly helpful for developing data-driven mobile applications that help optimize farming. Moreover, the blockchain addresses the challenge of creating a comprehensive secure infrastructure for IoT and integrating numerous technologies used in ICT e-agriculture.

Many smart farming models are proposed and implemented based on the joint application of IoT and blockchain technology. For example, Patil et al. (2017) propose "a lightweight blockchain-based architecture for smart greenhouse farms." In the greenhouses, IoT sensors act as a private local blockchain that centrally managed by the owner. Lin et al. (2018) propose a blockchain and IoT based smart agriculture framework for general use. The core of the framework is a platform that helps establish trust among actors using blockchain. Agents 


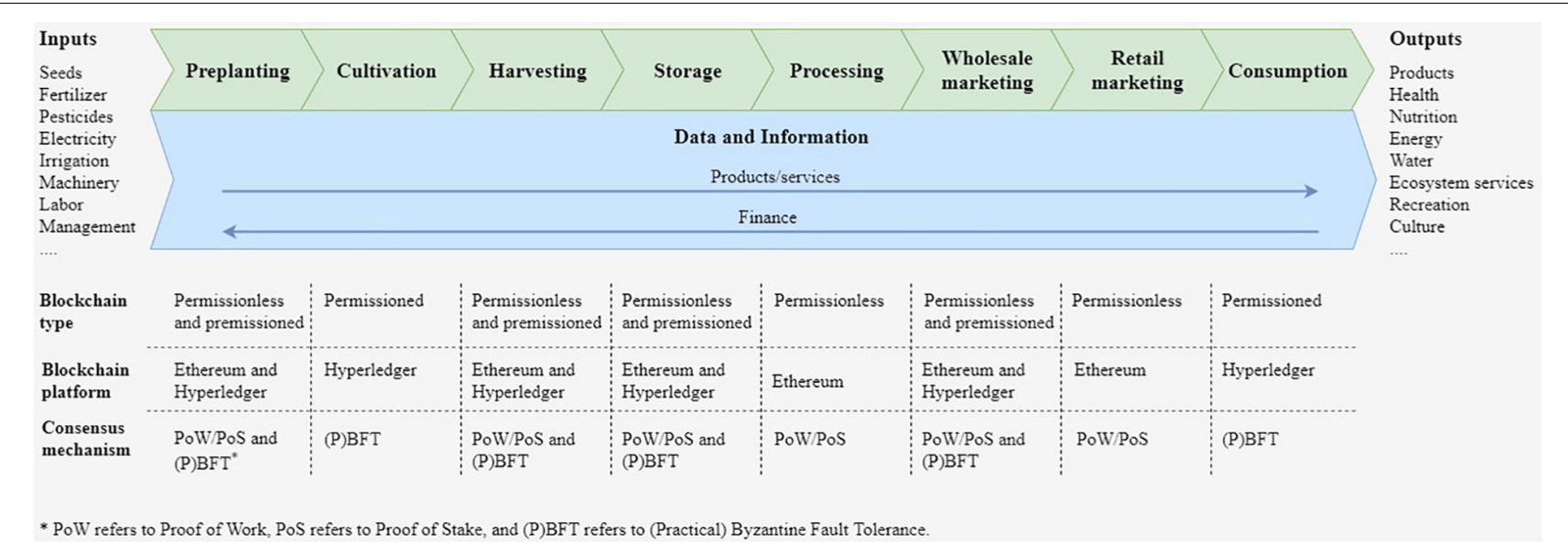

FIGURE 1 | Data and information flow along the food value chain.

related to products from its plantation to sale can access the data stored in the blockchain through smart mobile phones. Lin et al. (2017) propose a blockchain-based ICT e-agriculture model for the use at the local and regional scale, in which each actor has a piece of real-time water quality data stored in the blockchain. Many companies devote themselves to the blockchain application to smart agriculture. For example, the company Fliament provides devices for connecting physical objects and networks through smart farming technology. It developed penny-sized hardware that can handily be used with existing machines or devices through any connected USB port for securely transacting against a blockchain. Blockchain is also used by farm organizations to make their farming practice smarter. For example, farmland irrigation associations in Taiwan use blockchain to archive the data collectively and better interact with the public (Lin et al., 2017). Each association operates as a "public juridical person" and publish their own data and information about irrigation management to the blockchain that can be accessed by the public. The transparency evokes the public's contribution to irrigation management and increases its efforts to improve water resource use. Over time, the longitudinal database created using blockchain can be used to inform decision-making on such as the construction and maintenance of irrigation canals.

Smart agriculture with blockchain does not lower, if not raise, the technological barrier for farmers to participate. Importantly, it is better motivated to collect trustworthy data from large farmers than from smallholders for uploading to the blockchain. Large farmers are more likely to be involved in blockchain-based smart agriculture and benefit from it. This thus can create or increase the discrepancy between large farmers and smallholders.

\section{Food Supply Chain}

With increased globalization and intense competition in the market, food supply chains have become longer and more complex than ever before. There are some common problems in food supply chains such as food traceability, food safety and quality, food trust and supply chain inefficiency, which add additional risks on the entire society, economy and the health of human.

From the producers' perspective, the use of blockchain technology helps establish a trust relationship with consumers and build up the reputation of their products, by transparently providing individual product information in the blockchain. Enterprises can better achieve the value of their products and thus increase their competitiveness. This would make it difficult for suppliers of fraud and low-quality products to stay in markets and force all suppliers to improve the quality of products in the whole agricultural and food sectors. From the consumers' perspective, the blockchain makes true and reliable information about how food is produced and transacted available. It helps address consumers' concern about the safety, quality and environmental friendliness of food (Ge et al., 2017). The use of blockchain provides the possibility for consumers to interact with producers because consumers can understand the food production process more conveniently and in more detail. It supports consumers by removing obstacles in the exchange of goods to tighten their relationship, and thus strengthen consumer trust and confidence in food safety. From the regulatory agencies' perspective, blockchain makes reliable and accurate information available for them to carry out informed and efficient regulations (Zhou et al., 2016; Chen, 2018).

Blockchain is capable of recording the information of a product from its provenance to the retail store. It provides a secure and immutable way of storing data collected at the start of the supply chain, e.g., DNA of livestock animals, pesticide residues of grain or vegetables. Such information can be checked and verified by any party involved in the supply chain of the product. Collecting such data for all products can be very costly, but it can be done on samples. The transparence of such information can help detect, e.g., the containment of undeclared meat like happened in the 2013 horse meat scandal in Europe (Kamath, 2018; Montecchi et al., 2019).

Many solutions facilitated by blockchain technology have been proposed to improve the traceability of agricultural products. Tian (2016) proposes an agricultural food supply 
chain traceability system using Radio Frequency Identification (RFID), a non-contact automatic identification communication technology. It can trace products with trusted information in the entire supply chain. The use of blockchain guarantees that the records of production, process, store and distribution in the system are reliable and genuine. Caro et al. (2018) proposed blockchain-based traceability system that is seamlessly linked with IoT devices, which provide digital data of production and consumption. The traceability is achieved using both Ethereum and Hyperledger Sawtooth blockchain platforms.

Many companies have committed to exploring the application of blockchain technology in food safety management and actively carrying out into practice. For example, Wal-Mart, Alibaba, and JD.com are actively implementing blockchain food traceability projects and using blockchain technology to track the entire process of food production, processing and sales. In October 2016, retail giant Wal-Mart, Tsinghua University and IBM applied the Hyperledger blockchain system to food supply chain management, exploring the Chinese pork supply chain and the United States mango supply chain as a pilot to explore the practical application methods and benefits of blockchain technology. In March 2017, Alibaba and Australia Post explored the blockchain to combat food adulteration. In August 2017, the world's 10 largest food and fast-moving consumer goods (FMCG) suppliers, including Wal-Mart, Nestle, Dole, and Golden Food, reached a partnership with IBM integrating the blockchain into its supply chain so that food suppliers' misconduct can be detected more quickly. In this collaboration, IBM's blockchain platform is designed to help food companies improve the visibility and traceability of their supply chains and make food safer.

The current blockchain technology in the food supply chain is still in the early stages of development. At the same time, there are many immature and imperfect places in the process of blockchain technology implementation. Furthermore, the application of blockchain technology needs wide participation and collaboration of involving parties in the food supply chain, which is significant to play its full role. Due to its characteristics of transparency, security and decentralization, blockchain technology makes it possible to track the information of food quality in the entire supply chain. This helps prevent fraud in food transaction and reduce the costs of food supply chain management. All parties, including producers, consumers and government regulatory bodies, can thus be benefited.

\section{E-Commerce of Agricultural Products}

The e-commerce and trade of agricultural product face some crucial problems to solve. First, as Tiago et al. (2017) have demonstrated that consumer with high overall trust is more willing to purchase online, however, the basic information of agriculture products is not easy to be confirmed and trusted by consumers. Meanwhile, Cash on delivery and Logistics service are the most crucial challenges faced by e-commerce companies, especially in developing countries (Reddy and Divekar, 2014). Besides, e-commerce retailers also need to handle time-demanding small orders with diverse items (Boysen et al., 2019), which causes high operating costs for e-commerce companies.

Blockchain technology may provide proper solutions for many aspects of these problems: (1) information security. Blockchain technology provides private key encryption which is a powerful tool that provides the authentication requirements ( $\mathrm{Xu}$ et al., 2016). It can thus link the data of all aspects of planting and harvesting of agricultural products safely and unchangeably. (2) Supply chain management. Blockchain technology could enable supply chain management more efficiently than traditional monitoring mechanisms by lowering signaling costs for each entity (Chod et al., 2019). Every link in the supply chain the producer, the place of origin, the shipping company, the destination, the multimodal transport, the warehouse and the final last mile - represents a "block" of information, with the advantage of visibility, aggregation, validation, automation and resiliency (Babich and Hilary, 2018). (3) Payment methods. The blockchain provides a digital payment solution with zero rates. Furthermore, application of cryptocurrency in the transaction of agricultural products will reduce transaction costs more substantially. (4) Consumer confidence. Through the decentralized mechanism, the distributed accounting system of the blockchain is time-stamped, so that all information on the chain is transparent and unmodifiable. Consumers will be liberated from fakes and regain confidence in e-commerce (Karame, 2016). (5) Reduce the cost of farmers. Many agricultural products are produced by households. Due to the low transaction volume and small scale, traditional e-commerce is neither willing nor able to provide services for them, thus excluding these participants from the market. Blockchain technology can greatly reduce transaction costs and incorporate them into the market again.

Some companies are already using this technology for practice, although it may not be used in the whole process. For example, after using blockchain technology, all the goods in the Old Farmers' Shopping Mall, an e-commerce company in Hubei Province of China, can be traced back to the source and all the production information can be queried by customers ${ }^{4}$. Before the goods are put into the platform, detail information has been recorded including seeding, watering, fertilization and deworming ${ }^{5}$. They also provide basic knowledge of producers, transportation logistics, storage days, and storage temperature. Customers only need to scan the QR code on the goods, which is unique, and all the information will be available to visit. This method can effectively avoid the forgery of bad merchants, and reconstruct consumers trust in agricultural products from e-commerce and its suppliers.

The application of blockchain technology in e-commerce and trade of agricultural product is still in its infancy and the current case is not simply perfect. For example, how to ensure the authenticity of the uploading process of data into blockchain is still a problem. A potential solution in the

${ }^{4}$ https://new.qq.com/rain/a/20181217A12JDA, last accessed on September 25, 2019

${ }^{5}$ https://www.jinse.com/bitcoin/218040.html, last accessed on September 25, 2019 
future may be IoT. What's more, blockchain's characteristics of distributed, non-tamperable, traceable need to be more widely and deeply explored to improve the productivity and efficiency of agricultural production and trade.

\section{LIMITATIONS}

The blockchain technology enables the traceability of information in the food supply chain and thus helps improve food safety. It provides a secure way of storing and managing data, which facilitates the development and use of data-driven innovations for smart farming and smart index-based agriculture insurance. In addition, it can reduce transaction costs, which will benefit farmers' access to markets and generating new revenue streams. Despite enormous potential advantages, key limitations remain for applying the blockchain technology in agriculture and food sectors.

First, further research is required on the transacting parties' motivation to provide genuine and precise information to the blockchain ledger. This might be especially important in the case of smallholder farming. The information generated in the farming process is scattered and owned by individual farmers. Blockchain technologies' benefits for farmers might be dependent on the size of the farm. On the one hand, smaller farms could easily participate in a blockchain-based insurance market. On the other hand, collecting and integrating on-farm data might be more convenient for larger farms. Thus, future research should try to anticipate which farms could benefit an which could lose from the introduction of blockchain-based solutions.

\section{REFERENCES}

Babich, V., and Hilary, G. (2018). Distributed ledgers and operations: what operations management researchers should know about blockchain technology. Manuf. Serv. Oper. Manag. (forthcoming) (in press). doi: 10.2139/ssrn. 3131250

Barnett, B. J., Barrett, C. B., and Skees, J. R. (2008). Poverty traps and index-based risk transfer products. World Dev. 36, 1766-1785. doi: 10.1016/j.worlddev. 2007.10.016

Barnett, B. J., and Mahul, O. (2007). Weather index insurance for agriculture and rural areas in lower-income countries. Am. J. Agric. Econ. 89, 1241-1247. doi: 10.1111/j.1467-8276.2007.01091.x

Boysen, N., de Koster, R., and Weidinger, F. (2019). Warehousing in the E-commerce era: a survey. Eur. J. Oper. Res. 277, 396-411. doi: 10.1016/j.ejor. 2018.08.023

Brown, M. E. (2015). Satellite remote sensing in agriculture and food security assessment. Procedia Environ. Sci. 29:307. doi: 10.1016/j.proenv.2015.07.278

Caro, M. P., Ali, M. S., Vecchio, M., and Giaffreda, R. (2018). "Blockchain-based traceability in agri-food supply chain management: a practical implementation," in Proceedings of the 2018 IoT Vertical and Topical Summit on AgricultureTuscany (IOT Tuscany), (Tuscany: Institute of Electrical and Electronics Engineers), 1-4.

Chen, W. (2018). Administrative Rules and Regulations for the Introduction of Food Information Traceability in Blockchain. Ph.D. thesis, Shanghai Normal University, Shanghai.

Chod, J., Trichakis, N., Tsoukalas, G., Aspegren, H., and Weber, M. (2019). On the financing benefits of supply chain transparency and blockchain adoption. Manag. Sci. (forthcoming) (in press). doi: 10.2139/ssrn.3078945

Collier, Z. A., Bates, M. E., Wood, M. D., and Igor, L. (2014). Stakeholder engagement in dredged material management decisions. Sci. Total Environ. 496, 248-256. doi: 10.1016/j.scitotenv.2014.07.044
Second, obtaining the data uploaded to a blockchain can be very costly, which will be a barrier to the adoption of blockchain technology in the sector. The setup of distributed ledger itself may be relatively cheap, whereas collecting data required for making the ledger useful, e.g., DNA of livestock animals could be expensive. Sampling can reduce the cost, but it requires that the population of products for data collection is large. This means the average cost of data collection is lower for larger farms than smaller ones, which raises the concern of increasing the income discrepancy.

Third, blockchain does not directly seamlessly integrate with existing legacy systems. In order to be successfully implemented, the technology needs to be plugged into an existing database and legacy systems such as enterprise resource planning, warehousing management and manufacturing execution systems. Building an infrastructure to use the blockchain technology is often time-consuming. The middleware and communication protocol that can glue existing systems will be key.

\section{AUTHOR CONTRIBUTIONS}

TD wrote the section of the application in agricultural insurance. PW wrote the section of the application in food supply chains. JH wrote the section of the application in e-commerce of agricultural products. HX conceived the idea of the manuscript and wrote other sections of the manuscript. All authors read and approved the final manuscript.

Conradt, S., Finger, R., and Spörri, M. (2015). Flexible weather index-based insurance design. Clim. Risk Manag. 10, 106-117. doi: 10.1016/j.crm.2015. 06.003

Dalhaus, T., and Finger, R. (2016). Can gridded precipitation data and phenological observations reduce basis risk of weather index-based insurance? Weather Clim. Soc. 8, 409-419. doi: 10.1175/wcas-d-160020.1

Dalhaus, T., Musshoff, O., and Finger, R. (2018). Phenology information contributes to reduce temporal basis risk in agricultural weather index insurance. Sci. Rep. 8:46. doi: 10.1038/s41598-017-18 656-5

Finger, R., Dalhaus, T., Allendorf, J. S., and Hirsch, S. (2018). Determinants of downside risk exposure of dairy farms. Eur. Rev. Agric. Econ. 45, 641-674. doi: 10.1093/erae/jby012

Gatteschi, V., Lamberti, F., Demartini, C., Pranteda, C., and Santamaría, V. (2018). Blockchain and smart contracts for insurance: is the technology mature enough? Future Internet 10:20. doi: 10.3390/fi1002 0020

Ge, L., Brewster, C., Spek, J., Smeenk, A., Top, J., van Diepen, F., et al. (2017). Blockchain for Agriculture and Food: Findings from the Pilot Study. Wageningen Economic Research report; No. 2017-112. Wageningen: Wageningen Economic Research.

Harz, D., Gudgeon, L., Gervais, A., and Knottenbelt, W. J. (2019). "Balance: dynamic adjustment of cryptocurrency deposits," in Proceedings of the 2019 ACM SIGSAC Conference on Computer and Communications Security, (New York, NY: ACM), 1485-1502.

Haveson, S., Lau, A., and Wong, V. (2017). Protecting Farmers in Emerging Markets with Blockchain. Newyork, NY: Cornell Tech.

Iansiti, M., and Lakhani, K. R. (2017). The truth about blockchain. Harv. Bus. Rev. 95, 118-127. doi: 10.3390/s19153267 
Ibm Institute for Business Value (2015). Device Democracy: Saving the Future of the Internet of Things. Available at: https:/www.ibm.com/services/us/gbs/ thoughtleadership/internetofthings/ (accessed September 25, 2019).

Jha, S., Andre, B., and Jha, O. (2018). ARBOL: Smart Contract Weather Risk Protection for Agriculture. Available at: https://www.arbolmarket.com/wpcontent/uploads/2018/09/ARBOL_WP-1.pdf (accessed 15, 2018).

Just, R. E., Calvin, L., and Quiggin, J. (1999). Adverse selection in crop insurance: actuarial and asymmetric information incentives. Am. J. Agric. Econ. 81, 834849. doi: $10.2307 / 1244328$

Kaddu, S., and Haumba, E. N. (2016). "Promoting ICT based agricultural knowledge management for increased production by smallholder rural farmers in Uganda: a case of Communication and Information Technology for Agriculture and Rural Development (CITARD), Butaleja," in Proceedings of the 22nd Standing Conference of Eastern, Central and Southern Africa Library and Information Associations (SCECSAL XXII), Butaleja, 243-252.

Kamath, R. (2018). Food traceability on blockchain: Walmart's pork and mango pilots with IBM. J. Br. Blockchain Assoc. 1:3712.

Karame, G. (2016). "On the security and scalability of bitcoin's blockchain," in Proceedings of the 2016 ACM SIGSAC Conference on Computer and Communications Security, (New York, NY: Association for Computing Machinery), 1861-1862.

Kaske, D., Mvena, Z., and Sife, A. (2018). Mobile phone usage for accessing agricultural information in Southern Ethiopia. J. Agric. Food Inf. 19, 284-298. doi: 10.1080/10496505.2017.1371023

Leblois, A., Quirion, P., and Sultan, B. (2014). Price vs. weather shock hedging for cash crops: ex ante evaluation for cotton producers in Cameroon. Ecol. Econ. 101, 67-80. doi: 10.1016/j.ecolecon.2014.02.021

Lesk, C., Rowhani, P., and Ramankutty, N. (2016). Influence of extreme weather disasters on global crop production. Nature 529:84. doi: 10.1038/nature16467

Lin, J., Shen, Z., Zhang, A., and Chai, Y. (2018). "Blockchain and IoT based Food Traceability for Smart Agriculture," in Proceedings of the 3rd International Conference on Crowd Science and Engineering, (New York, NY: Association for Computing Machinery), 3.

Lin, Y. P., Petway, J., Anthony, J., Mukhtar, H., Liao, S. W., Chou, C. F., et al. (2017). Blockchain: the evolutionary next step for ICT E-agriculture. Environments 4:50. doi: 10.3390/environments 4030050

Lobell, D. B., Schlenker, W., and Costa-Roberts, J. (2011). Climate trends and global crop production since 1980. Science 333, 616-620. doi: 10.1126/science. 1204531

Miranda, M. J., and Glauber, J. W. (1997). Systemic risk, reinsurance, and the failure of crop insurance markets. Am. J. Agric. Econ. 79, 206-215. doi: 10.2307/ 1243954

Montecchi, M., Plangger, K., and Etter, M. (2019). It's real, trust me! Establishing supply chain provenance using blockchain. Bus. Horiz. 62, 283-293. doi: 10 . 1016/j.bushor.2019.01.008

Mussenbrock (2017). Etherisc - White Paper. Available at: https://etherisc.com/ \#downloads (accessed November 15, 2018).

Ngo Monitor (2015). Amnesty International: Failed Methodology, Corruption, and Anti-Israel Bias. Jerusalem: NGO Monitor.
Patil, A. S., Tama, B. A., Park, Y., and Rhee, K. H. (2017). “A framework for blockchain based secure smart green house farming," in Advances in Computer Science and Ubiquitous Computing, eds J. Park, V. Loia, G. Yi, and Y. Sung, (Singapore: Springer), 1162-1167. doi: 10.1007/978-981-10-7605-3_185

Reddy, N. A., and Divekar, B. R. (2014). A study of challenges faced by E-commerce companies in India and methods employed to overcome them. Procedia Econ. Financ. 11, 553-560. doi: 10.1016/s2212-5671(14)00220-2

Ritter, M., Musshoff, O., and Odening, M. (2014). Minimizing geographical basis risk of weather derivatives using a multi-site rainfall model. Comput. Econ. 44, 67-86. doi: 10.1007/s10614-013-9410-y

Sylvester, G. (2019). E-agriculture in Action: Blockchain for Agriculture (Opportunities and Challenges). Bangkok: International Telecommunication Union (ITU).

Tiago, O., Alhinho, M., Rita, P., and Dhillon, G. (2017). Modelling and testing consumer trust dimensions in e-commerce. Comput. Human Behav. 71, 153164. doi: 10.1016/j.chb.2017.01.050

Tian, F. (2016). "An agri-food supply chain traceability system for China based on RFID \& blockchain technology," in Proceedings of the 2016 13th international conference on service systems and service management (ICSSSM) (Piscataway, NJ: IEEE), 1-6.

Turvey, C. G. (2001). Weather derivatives for specific event risks in agriculture. Rev. Agric. Econ. 23, 333-351. doi: 10.1111/1467-9353.00065

Vroege, W., Dalhaus, T., and Finger, R. (2019). Index insurances for grasslands - a review for Europe and North-America. Agric. Syst. 168, 101-111. doi: 10.1016/ j.agsy.2018.10.009

Walter, A., Finger, R., Huber, R., and Buchmann, N. (2017). Opinion: smart farming is key to developing sustainable agriculture. Proc. Natl. Acad. Sci. U. S. A. 114, 6148-6150. doi: 10.1073/pnas.1707462114

Woodard, J. D., and Garcia, P. (2008). Basis risk and weather hedging effectiveness. Agric. Financ. Rev. 68, 99-117. doi: 10.1108/00214660880001221

Xu, X., Pautasso, C., Zhu, L., Gramoli, V., Ponomarev, A., Tran, A. B., et al. (2016). "The blockchain as a software connector," in Proceedings of the 2016 13th Working IEEE/IFIP Conference on Software Architecture (WICSA), (Piscataway, NJ: Institute of Electrical and Electronics Engineers), 182-191.

Yousefi, M. R., and Razdari, A. M. (2015). Application of GIS and GPS in precision agriculture (a Review). Int. J. Adv. Biol. Biomed. Res. 3, 7-9.

Zhou, Q., Wang, Y., and Fu, X. (2016). Information asymmetry, blockchain and food safety. Res. China Mark. Superv. 11, 53-56. doi: 10.3390/ijerph15081627

Conflict of Interest: The authors declare that the research was conducted in the absence of any commercial or financial relationships that could be construed as a potential conflict of interest.

Copyright (c) 2020 Xiong, Dalhaus, Wang and Huang. This is an open-access article distributed under the terms of the Creative Commons Attribution License (CC BY). The use, distribution or reproduction in other forums is permitted, provided the original author(s) and the copyright owner(s) are credited and that the original publication in this journal is cited, in accordance with accepted academic practice. No use, distribution or reproduction is permitted which does not comply with these terms. 